\title{
An unusual cause of postmenopausal vaginal haemorrhage: a case report
}

\author{
Junyan Sun', Ying Guo', Li Ma², Zhaoxia Qian and Dongmei Lai ${ }^{1 *}$
}

\begin{abstract}
Background: Post-menopause vaginal haemorrhage is typically related to gynaecological malignancies. Bleeding from vaginal varices rarely occurs, especially in nonpregnant women. Moreover, nonpregnancyrelated causes of vaginal varicosities include portal hypertension, especially that caused by liver cirrhosis, pelvic congestion syndrome and Klippel-Trenaunay syndrome or Parkes-Weber syndrome. Here, we report an unusual cause of nonpregnancy-associated vaginal variceal bleeding.

Case presentation: A 55-year-old postmenopausal woman presented in our outpatient department with complaints of recurrent bloody vaginal discharge. A group of varicose veins and several haemorrhagic spots were found on her vaginal wall during a vaginal speculum examination. Genital cancers were excluded by colposcopy and transvaginal ultrasonography; furthermore, a pelvic arteriovenous fistula was not found on a pelvic computed tomography $(\mathrm{CT})$ scan. However, congenital varicosities and deep arteriovenous shunts were observed in her left leg on arterial angiography. Moreover, vaginal bleeding was improved after resolution of the underlying deep arteriovenous shunts in her left leg. Therefore, congenital arteriovenous shunts and elevated inferior vena cava pressure might be responsible for her recurrent vaginal varicose bleeding.
\end{abstract}

Conclusion: Haemorrhage due to vaginal varices is easily detected with a vaginal speculum examination. However, diagnosis and treatment of the original disease are important after bleeding is controlled.

Keywords: Postmenopausal vaginal bleeding, Vaginal varicosities, Deep arteriovenous shunts

\section{Introduction}

Postmenopausal vaginal bleeding is a frequent medical problem with a prevalence rate as high as $10 \%$ in the general population $[1,2]$. The causes of postmenopausal bleeding include vaginal or endometrial atrophy, hormone replacement therapy (HRT), endometrial cancer, endometrial or cervical polyps, and endometrial hyperplasia [3, 4]. Vaginal varicosities are part of a larger set of complications that can occur as a result of venous congestion and obstruction in both pregnant and nonpregnant patients. The occurrence of vaginal varicosities during pregnancy is less common than the occurrence vulvar varicosities, which occur in $2-4 \%$ of pregnancies [5-7]. Nonpregnancy-related causes of vaginal varicosities include portal hypertension, especially that caused

\footnotetext{
* Correspondence: laidongmei@hotmail.com

${ }^{1}$ The International Peace Maternity and Child Health Hospital, School of Medicine, Shanghai Jiaotong University, 145, Guang-yuan Road, Xuhui District, Shanghai 200030, China

Full list of author information is available at the end of the article
}

by liver cirrhosis, pelvic congestion syndrome and Klippel-Trenaunay syndrome or Parkes-Weber syndrome [8-11]. Here, we report a postmenopausal woman with vaginal varicose bleeding who presented to our outpatient department and had neither abnormal liver function nor pelvic congestion syndrome.

\section{Case presentation}

A 55-year-old postmenopausal woman presented in our outpatient department because of increasingly serious vaginal bleeding in the previous 2 years. She had experienced a caesarean delivery at 28 years old and underwent natural menopause at 53 years old. The bleeding, which followed a severe cough, was less than normal menses at first but later was heavy and left her clothes soaking wet. The patient reported that the bleeding was fresh blood, which could be stanched by compression in a sitting position. At the time of admission, a vaginal speculum examination showed that the vaginal wall had many varicosities and some bleeding spots. To exclude malignant 
A

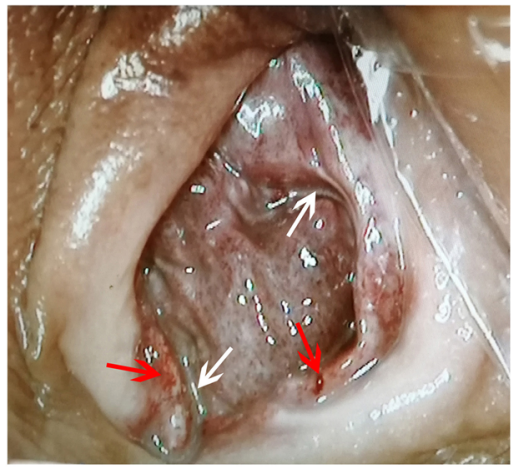

B

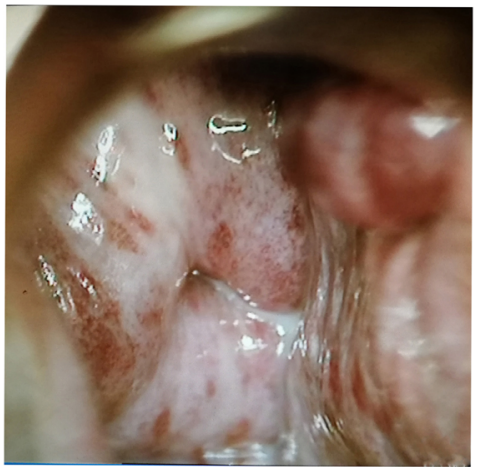

Fig. 1 lodine staining of the vaginal wall and cervix as shown by colposcopy. a The vaginal wall exhibited many varicosities and some bleeding spots. b Uterine cervix with iodine staining; no lesions were found in the cervix. White arrows: varicosities in the vaginal wall. Red arrows: bleeding spots

diseases, the patient underwent colposcopy, and the varicosities and bleeding spots were further confirmed in the vaginal mucosa (Fig. 1a). However, iodine staining showed no lesions on the mucosae (Fig. 1b). In addition, the endometrial thickness was less than $4 \mathrm{~mm}$ according to transvaginal ultrasonography.

Simultaneously, we noticed that the patient had obvious venous varicosities in her left leg and that the diameter of the left leg was significantly larger than that of the right leg (Fig. 2a). She stated that the venous varicosities were found when she was 10 years old but not treated because of poor medical conditions. To exclude vascular malformation, we advised the patient to visit the vascular surgery department. On contrast-enhanced computed tomography (CT) scanning of the legs, several varicosities and hyperplastic soft tissue and muscle were found in the left leg but not in the right leg (Fig. 2b). To determine whether multiple arteriovenous malformations were present, the patient underwent a CT scan of the pelvis, which showed some venous varicosities in the left internal pudendal vein but not in the right vein (Fig. 3a). However, pelvic arteriovenous shunts and pelvic congestion syndrome were not found on the 3-D reconstructed image (Fig. 3b).

Then, deep arteriovenous shunts in the left leg were found by arterial angiography. The arteriovenous shunts were partly closed by an interventional arteriovenous fistula occlusion operation at Zhongshan Hospital, Fudan University, Shanghai, China. Aspirin and Plavix were given after surgery as anticoagulants for 1 month and were gradually stopped over the next 2 months. The vaginal bleeding was gradually alleviated and disappeared 5 months later. For long-term management, close observation and regular follow-up examinations were recommended.

\section{Discussion and conclusion}

Postmenopausal bleeding is often associated with either a benign or malignant endometrial abnormalities [12].

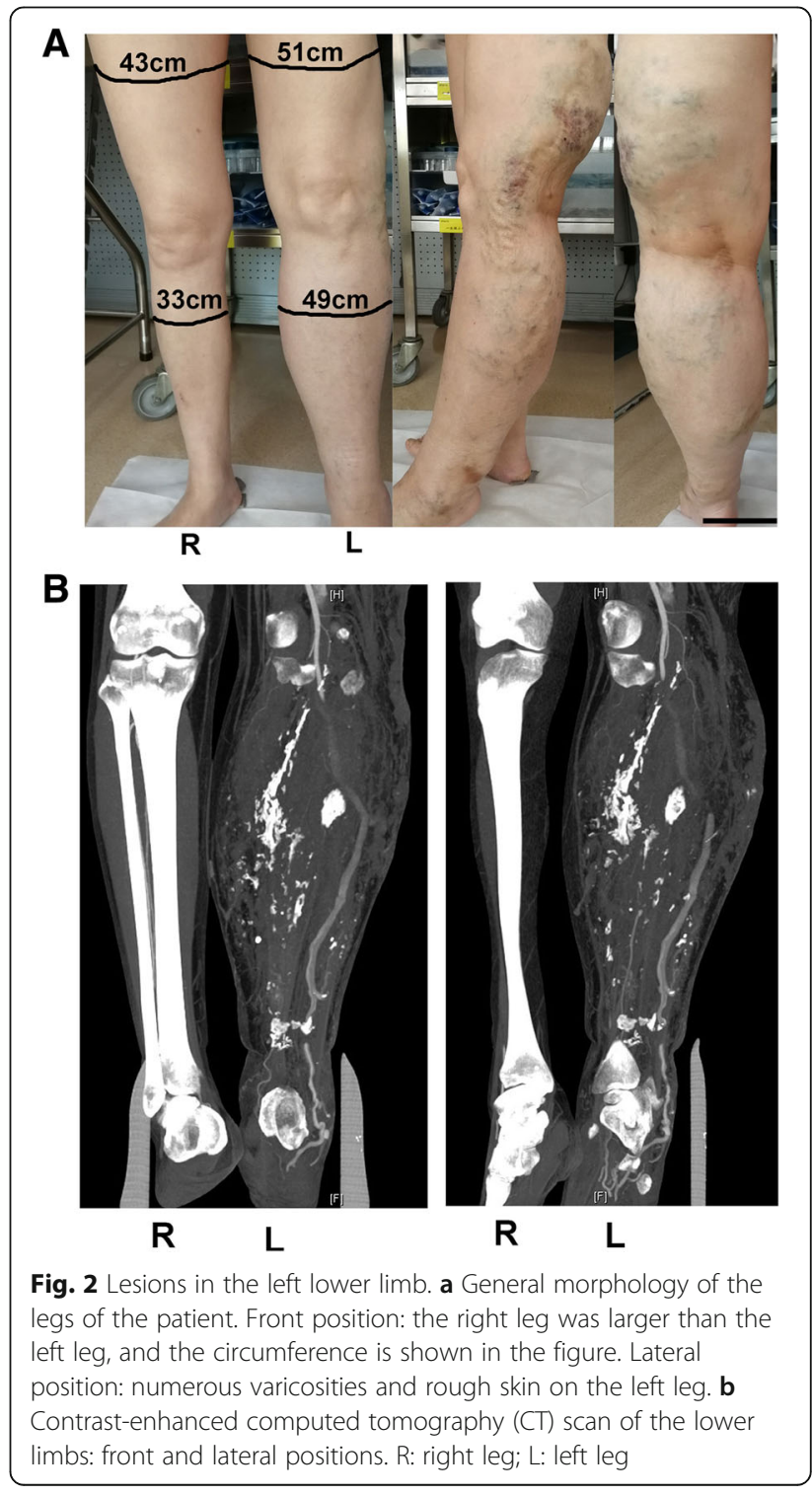



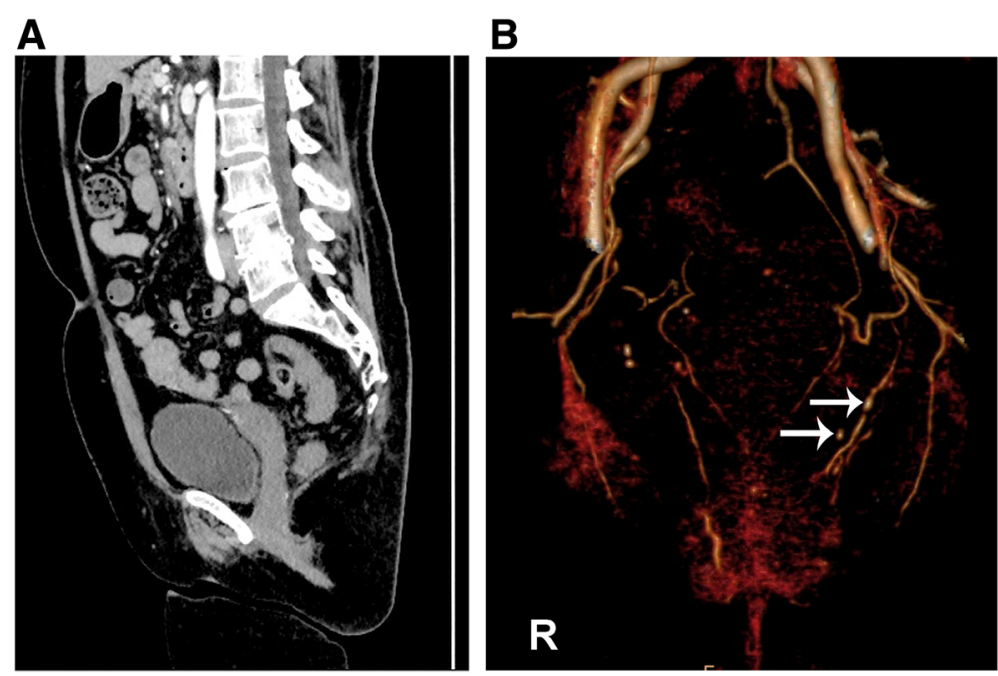

Fig. 3 Lesions in the pelvic cavity. a Contrast-enhanced computed tomography (CT) scan of the abdomen and pelvic cavity. b 3-D reconstruction of the pelvic vessels. White arrows: enlarged vein and varicosities in the left pelvic region. R: right side

However, haemorrhages from vaginal varices have been reportedly caused by arteriovenous malformations secondary to portal hypertension in cirrhotic patients and pelvic congestion syndrome in postmenopausal women $[8$, $11,13]$. Bleeding caused by increased central venous pressure, as in this case, has rarely been reported. However, we could not exclude the possibility of Parkes-Weber syndrome in this patient, which is a clinical disorder consisting of capillary malformation, soft tissue and bone hypertrophy, venous and lymphatic malformations and/or mutations in the RASA 1 gene $[14,15]$. Although the patient had vaginal varices, congenital arteriovenous malformations and soft tissue hypertrophy in the left limb, there was no evidence of capillary malformation or RASA 1 gene mutation.

Vulvovaginal varices are often found during pregnancy, usually developing after 12-26 weeks of pregnancy, and largely self-resolve shortly after delivery [16-18]. Pregnancy itself causes several physiological changes that favour varicosity formation. Much of the literature focuses on vulvar varicosities during pregnancy because vaginal venous flow occurs via a venous plexus that communicates with numerous plexuses, such as the vesical and haemorrhoidal plexuses [19]. Furthermore, vulvovaginal varicosities are aggravated by delivery, as described by Pratilas and colleagues [20]. In that case, the 34-year-old patient carried one male foetus delivered via $\mathrm{C}$-section, and the vaginal varicosities were found during pregnancy. However, the symptoms did not spontaneously resolve during the postpartum period.

In most cases, the treatment of vaginal variceal bleeding comprises two stages: controlling the haemorrhage and, subsequently, determining the cause and curing the underlying disease $[8,21]$. In this case, when the patient initially visited our department, the vaginal bleeding had stopped. At that time, benign or malignant genital diseases were excluded. Considering her recurrent vaginal bleeding, we advised the patient to seek treatment for the underlying disease. Five months after her limb surgery, the bleeding was significantly reduced. Thus, the vaginal bleeding might have occurred secondary to the increased central venous pressure caused by the arteriovenous shunts in her leg.

Vaginal variceal bleeding decreases the quality of life, especially in postmenopausal women. First, vaginal bleeding should be considered when the discharge consists of fresh blood. Then, a vaginal speculum examination should be carefully conducted. Furthermore, it is important to determine and cure the underlying disease after the bleeding is controlled.

\section{Abbreviations}

$\mathrm{CT}$ : Computed tomography; HRT: Hormone replacement therapy

\section{Acknowledgements}

Not applicable.

\section{Funding}

This work was supported by the National Natural Science Foundation of China (No. 81741013 to Domgmei Lai, PhD).

\section{Availability of data and materials}

All data related to this case report are available from the corresponding author on reasonable request.

\section{Authors' contributions}

JYS and GY reviewed the pathological diagnosis, drafted the manuscript and performed the literature review. DML, LM and ZXQ confirmed the diagnosis, drafted the manuscript and performed the literature review. All authors read and approved the final manuscript. 


\section{Ethics approval and consent to participate}

The study was approved by the Ethics Committees of the International Peace Maternity and Child Health Hospital, and the patient provided written informed consent.

\section{Consent for publication}

Written informed consent was obtained from this patient.

\section{Competing interests}

The authors declare that they have no competing interests.

\section{Publisher's Note}

Springer Nature remains neutral with regard to jurisdictional claims in published maps and institutional affiliations.

\section{Author details}

${ }^{1}$ The International Peace Maternity and Child Health Hospital, School of Medicine, Shanghai Jiaotong University, 145, Guang-yuan Road, Xuhui District, Shanghai 200030, China. ${ }^{2}$ Zhangshan Hospital, Fudan University, 180, Fenglin Road, Xuhui District, Shanghai 200032, China.

Received: 14 November 2018 Accepted: 30 January 2019

Published online: 07 February 2019

\section{References}

1. Astrup K, Olivarius Nde F. Frequency of spontaneously occurring postmenopausal bleeding in the general population. Acta Obstet Gynecol Scand. 2004;83(2):203-7.

2. Breijer MC, Mol BW. Transvaginal ultrasound measurement of the endometrium remains the first line test for investigating postmenopausal bleeding but integration of patient characteristics into testing may further improve diagnostic algorithms. BJOG. 2016;123(3):447.

3. Salman MC, Bozdag G, Dogan S, Yuce K. Role of postmenopausal bleeding pattern and women's age in the prediction of endometrial cancer. Aust N Z J Obstet Gynaecol. 2013;53(5):484-8

4. Smith PP, O'Connor S, Gupta J, Clark TJ. Recurrent postmenopausal bleeding: a prospective cohort study. J Minim Invasive Gynecol. 2014; 21(5):799-803.

5. Adler SS. Extensive varix of vulva and vagina in full term pregnancy; delivery by cesarean section. Am J Obstet Gynecol. 1946;51:272-4.

6. Orlando G, Goffette P, Geubel A, Lerut J. Vaginal bleeding complicating portal hypertension: a particular entity - report of two cases and review of the literature. Transpl Int. 2005;18(12):1382-5.

7. Taylor WE. Rupture of vaginal varicosities simulating placenta previa. Minn Med. 1958;41(5):347 passim.

8. Chan G, Taqi A, Drage M, Quan D. A case report of massive vaginal variceal hemorrhage in a patient with cirrhosis secondary to nonalcoholic steatohepatitis unresolved even after successful liver transplantation. Transplant Proc. 2013;45(2):835-7.

9. Eriksson LS, Hardstedt C, Law DH, Thulin L. Massive haemorrhage from vaginal varicose veins in patient with liver cirrhosis. Lancet. 1982; 1(8282):1180

10. Brown CL, Rizer M, Alexander R, Sharpe EE 3rd, Rochon PJ. Pelvic congestion syndrome: systematic review of treatment success. Semin Interv Radiol. 2018;35(1):35-40.

11. Turkmen M, Kavukcu S, Cakmakci H, Soylu A, Aktan S, Cagan Y. A girl of Klippel-Trenaunay weber syndrome coexistence of recurrent bloody vaginal discharge. Int Urol Nephrol. 2010;42(3):575-8.

12. Breijer MC, Timmermans A, van Doorn HC, Mol BW, Opmeer BC. Diagnostic strategies for postmenopausal bleeding. Obstet Gynecol Int 2010;2010:850812.

13. Glick JE, Reyes I. An unusual cause of vaginal bleeding. J Emergency Med. 2016;51(3):322-3.

14. Bell D, Kane PB, Liang S, Conway C, Tornos C. Vulvar varices: an uncommon entity in surgical pathology. Int J Gynecol Pathol. 2007;26(1):99-101.

15. al-Salman MM. Klippel-Trenaunay syndrome: clinical features, complications, and management. Surg Today. 1997;27(8):735-40.

16. Furuta N, Kondoh E, Yamada S, Kawasaki K, Ueda A, Mogami H, Konishi I. Vaginal delivery in the presence of huge vulvar varicosities: a case report with MRI evaluation. Eur J Obstet Gynecol Reprod Biol. 2013;167(2):127-31.
17. Jindal S, Dedhia A, Tambe S, Jerajani H. Vulvovaginal varicosities: An uncommon sight in a dermatology clinic. Indian J Dermatol. 2014;59(2):210.

18. Leung SW, Leung PL, Yuen PM, Rogers MS. Isolated vulval varicosity in the non-pregnant state: a case report with review of the treatment options. Aust N Z J Obstet Gynaecol. 2005;45(3):254-6.

19. McHugh PP, Jeon H, Gedaly R, Johnston TD, Depriest PD, Ranjan D. Vaginal varices with massive hemorrhage in a patient with nonalcoholic steatohepatitis and portal hypertension: successful treatment with liver transplantation. Liver Transpl. 2008;14(10):1538-40.

20. Pratilas GC, Dinas K. Severe vulvovaginal varicosities in pregnancy. N Engl J Med. 2018:378(22):2123.

21. Garg M, Lee S, Brooks M, Gow P. Education and imaging. Hepatobiliary and pancreatic: bleeding vaginal varices. J Gastroenterol Hepatol. 2012;27(1):185.
Ready to submit your research? Choose BMC and benefit from:

- fast, convenient online submission

- thorough peer review by experienced researchers in your field

- rapid publication on acceptance

- support for research data, including large and complex data types

- gold Open Access which fosters wider collaboration and increased citations

- maximum visibility for your research: over $100 \mathrm{M}$ website views per year

At BMC, research is always in progress.

Learn more biomedcentral.com/submissions 